\title{
الأخطاء الثائعة في كتابة الحروف العربية لدى الطلاب في قسم تعليم اللغة العربية بجامعة سلاتيجا الإسلامية الحكومية
}

\author{
Burhan Yusuf Habibi \\ Institut Agama Islam Negeri (IAIN) Salatiga \\ burhanyusufhabibi@iainsalatiga.ac.id
}

\begin{abstract}
Abstrak
Penelitian ini bertujuan untuk mengungkap kesalahan-kesalahan yang seringkali terjadi dalam penulisan huruf-huruf Arab oleh mahasiswa jurusan Pendidikan Bahasa Arab (PBA) IAIN Salatiga dan langkah-langkah strategis untuk memperbaikinya. Penelitian ini menggunakan metode kualitatif deskriptif dengan menggunakan observasi sebagai instrumen utamanya untuk mendeskripsikan dan menganalisis data dari sample yang diambil. Populasi dalam penelitian ini yaitu mahasiswa PBA semester 1, sedangkan sample diambil secara acak sesuai dengan kebutuhan. Ada 10 sample hasil tulisan mahasiswa yang dikaji, dideskripsikan lalu dianalisis. Setelah itu dilakukakan identifikasi dan klasifikasi kesalahan penulisan yang dilakukan oleh mahasiswa. Hasil penelitian ini menunjukkan adanya kesalahan-kesalahan penulisan huruf Arab dalam bentuknya dan lemahnya kemampuan meletakkan huruf pada posisinya secara umum. Selain itu, terdapat kesalahan dalam memberikan jarak baik antar huruf maupun antar kata. Sebagian ungkapan dan huruf tidak bisa terbaca dengan sempurna. Terdapat ketidak konsistenan bentuk penulisan huruf terhadap garis, baik huruf yang berada di atas garis maupun di bawahnya.
\end{abstract}

Kata kunci: kesalahan-kesalahan umum, penulisan, kaligrafi, huruf Arab

$$
\begin{aligned}
& \text { المستخلص } \\
& \text { هدفت هذه الدراسة إلى الكشف عن الأخطاء الشائعة في كتابة الحروف العربية لدى الطلاب في } \\
& \text { قسم تعليم اللغة العربية بجامعة سلاتيجا الإسلامية الحكومية والخطط لتصحيحها. وقد تم انتهاج } \\
& \text { المنهج الوصفي، واستخدمت الملاحظة كأداة أساسية في وصف وتحليل بيانات العينات قيد } \\
& \text { الدراسة. وقد مثل مجتمع الدراسة طلاب قسم تعليم اللغة العرية في المرحلة الأولى. وبلغ حجمها } \\
& \text { عشر عينات من الاعمال حيث تمت دارستها وصفها وتحليلها، وهي من كارسات الطلاب. وتم } \\
& \text { اختيارها بحيث يتوافر فيها نص كتابي يقبل الوصف والتحليل. ومن أهم النتائج التي توصلت إليها } \\
& \text { الدارسة: أن هناك الأخطاء في عدم مراعاة حجم الحرف، وطوله، وقصره. وعدم مراعات التناسب } \\
& \text { بين الحروف طولا واتساعا، ولا يراعى البعد بين الكلمات في مسافات ثابتة، ولا يتبع قواعد رسم } \\
& \text { الحروف، وقد اتضح أيضًا أن السياق العام للنصوص أن الحروف ذوات الكاسات (الحروف }
\end{aligned}
$$


النازلة تحت السطر) لا ترسم على حالها الطبيعي. وعدم الالنزام بسطر الحروف النازلة تحت سطر الكتابة الأساسي. الكلمات المفتاحية: الأخطاء الشائعة، الكتابة، الخط العربي، الحروف العربية

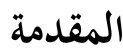

الكتابة هي عملية ضرورية للحياة العصرية سواء بالنسبة للفرد أم بالنسبة للمجتمع، ومن ثم

تعتبر الكتابة الصحيحة عملية مهمة في تعليم اللغة باعتبارها عنصر أساسي من عناصر الثقافة. وضرورة اجتماعية لنقل الأفكار والتعبير عنها للوقوف على أفكار الآخرين والإلمام بها، وفي إطار النظرة التكاملية للغة، إن تدريب الطالب علي الكتابة يتركز في العناية بثلاثة أنواع من القدرات؛ قدرة في الخط، وقدرة في الهجاء، وقدرة في التعبير الكتابي الجيد. (عمر، 2008: 112). والمبدأ الأساسي لذلك هو رسم الحروف العربية بشكل صحيح سليم على قواعدها. الخط والتهجى وسيلتان للاتصال الكتابي. فليس المهم أن تكون الكتابة سليمة واضحة، ولا يكون الخط جميلا فحسب، ولكن المهم حقيقة هو أن تساعد الكتابة الواضحة والخط الجميل الكاتب في أن يضع أفكاره في شكل مكتوب يمكن قراءته بسهولة. وعلى هذا فالرسم السليم والخط الواضح يستخدمان لتحويل المعانى إلى لغة رمزية يمكن فهمها (مدكور، 2016:

وكثير من متعلمي العربية في إندونيسيا صغارا وكبارا يجدون صعوبة في تعلم الكتابة وخصوصا في رسم حروفها، بل هناك الأخطاء الشائعة في كتابتهم ولو كانوا من طلاب الجامعة

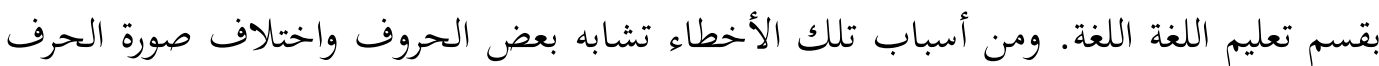
الواحد باختلاف موضعه من الكلمة، ونقط الحروف، ووصل الحروف وفصلها، والخلط بين الصوائب الطوال والقصار. ولو كان الطلاب قد تعلموا كيفية تصوير الحروف منفردة ومتصلة في شكل كلمات، لكن كتاباتهم تبقى نسبية: أحجام الحروف متفاوتة في الكلمة الواحدة، يتنقصها التناسق و التناغم فيما بينها، وقد نجد حروفا مشوهة لأن التلاميذ لم يحترموا الاتجاه المناسب في رسمها

وفي هذه الدراسة أراد الباحث أن يكشف الأخطاء الشائعة في كتابة الحروف العبية لدى الطلاب بقسم تعليم اللغة العربية بجامعة سلاتيجا الإسلامية الحكومية. وبعد تحديدها وتشخيصها يمكن لمعلمي الخط والإملأ أن يعرف الأنشطة والاقتراحات لتحسين وتصحيح تلك لـ لتك الأخطاء، حتى أن تكون كتابة الطلاب سليمة وسهلة لقراءتها. 


\section{منهجية البحث}

يستخدم في هذه الدراسة المنهج الوصفي التحليلي باعتباره أنسب المناهج لإجراء مثل

هذه الدراسة، وذلك لأنه يلائم طبيعة مشكلة الدراسة ويساعد في إلقاء الضوء على جوانبها المختلفة عن طريق الوصف والتحليل، وهو أحد مناهج البحث العلمي المعرفة بمحاولة الوصول إلى المعرفة الدقيقة والتفصيلية لعناصر مشكلة أو ظاهرة قائمة، للوصول إلى فهم أفضل وأدق أو وضع السياسات والإجراءات المستقبلية الخاصة بها (الرفاعي، 1998: 122). واستخدمت الملاحظة كأداة أساسية في وصف وتحليل بيانات العينات قيد الدراسة.

وقد مثل مجتمع الدراسة طلاب قسم تعليم اللغة العربية للسنة الأولى بجامعة سلاتيجا الإسلامية الحكومية، و هي عينة غير احتمالية (منتظمة)، تم اختيارها بالأسلوب القصدي. وبلغ حجمها عشر عينات من كتابة الطلاب بالصور القصيرة في القرآن الكريم حيث تمت دارستها وصفها وتحليلها، وهي من كارسات التلاميذ. العينة تكون هي الصفات التي تتصف بها غالب مفردات المجتمع محل البحث. وتم اختيارها بحيث يتوافر فيها نص كتابي يقبل الوصف والتحليل.

\section{مفهوم الكتابة وأهميتها}

حاول العديد من المشتغلين بتعليم الكتابة تعريف مفهومها وتحديدها للوصول على تصور إجرائي يمكن تعليمها في ضوءه. وبالرغم من وضوح بعض هذه التعريفات وغموض البعض بـ بـات الأخر، إلا أنها -في مجموعها- تكاد تدور حول معنى واحد للكتابة، ومفهوم إجرائي ذي ثلاثة أبعاد (الناقة، 2017: 341).

يرى سعيد لافي (2015: 217) أن الكتابة هي رسم الحروف والكلمات والجمل وفقا للقواعد الإملائية المتعارف عليها. وير البعض أنها عملية تمثيل الرموز الصوتية برموز خطية مرسومة على سطح، وهذا التعريف يعنى أنها خط وتهجي. ويرى البعض الأخر أنها مهارة تشكيل الحروف باليد (مناصرة: دون السنة، 113-114)، وهذا يعنى أنها خط، ولكن بمفهوم ضيق للخط.

وقيل أيضا أنها إعادة ترميز للغة المنطوقة في شكل خطي على الورق، من خلال أشكال ترتبط بعضها ببعض، وفق نظام معروف اصطلح عليه أصحاب اللغة، بحيث يعد كل شكل من هشه الأشكال مقابلا لصوت لغوي يدل عليه (خط، تهجي)، وذلك بغرض نقل الأفكار والآراء والمشاعر من كاتب إلى قراء بوصفهم مستقبلين (تعبير تحرير). وهناك من يعرف الكتابة بأنا رسم لكم لكابه لأشكال الحروف بشكل واضح وجميل (الخط) وأنها رسم الكلمات بشكل سليم من حيث: 
الهجاء. وعلمات الترقيم، وكتابة بعض الظواهر في اللغة، كالهمزة مثلا، والألف المقصور والمنقوص

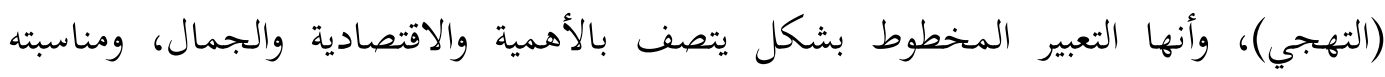

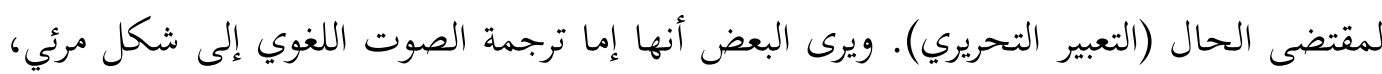

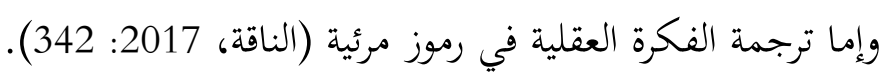

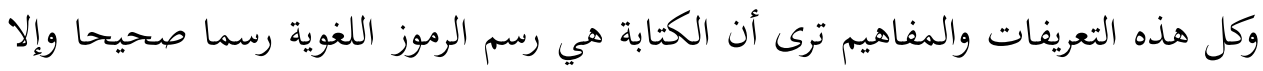

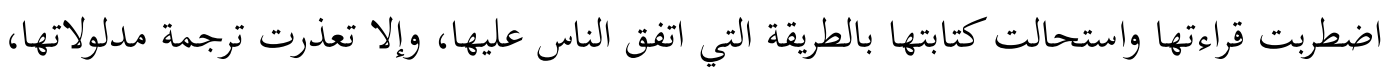

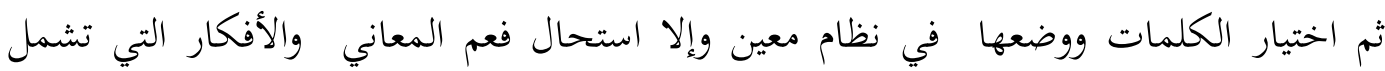

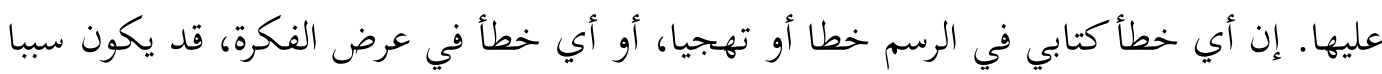

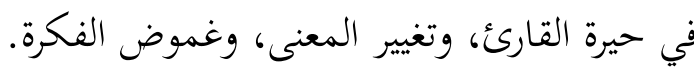
تعد الكتابة من أهم وسائل الاتصال التي يستطيع الفرد من خلالها التعبير عن أفكاره،

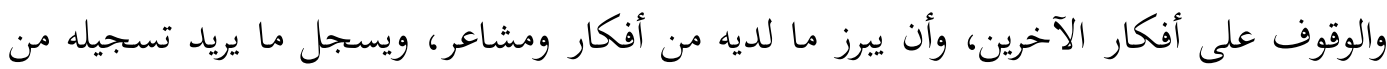

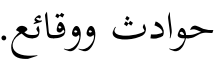
وتعتبر الكتابة الصحيحة عملية مهمه للمتعلم في دراسته، وحياته المستقبلة. وتدريب المتعلمين على الكتابة في مراحل التعليم المختلفة ينبغي أن يتركز على تنمية المهارتين

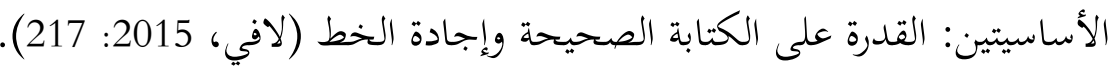

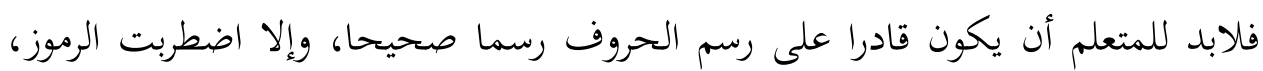
واستحالت قراءتها، ولابد أن تتوافر في الكتابة قواعد الخط التي يترتب عليها حسني حسنه، ومن ثم فهم

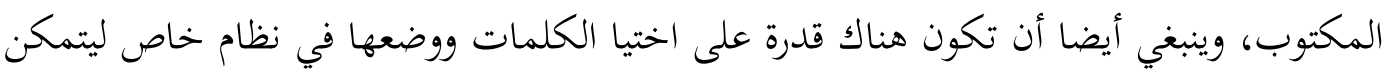
القارئ من فهم المكتوب والمعنى والأفكار دون عناء.

\section{مقووئية الكتابة العربية}

المقروئية هي سهولة استيعاب العين للشكل المكتوب في مجال القراءة (بمعنى تمييزه)،

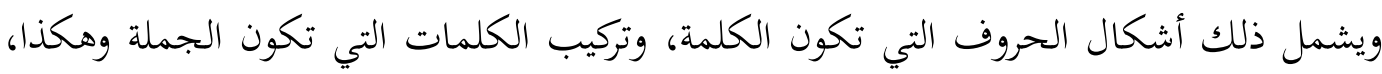

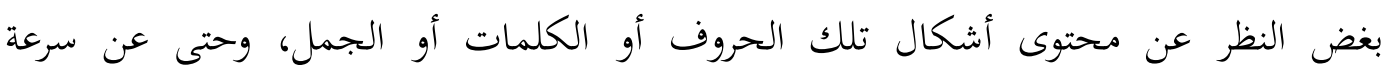

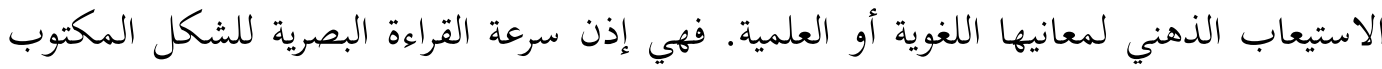
والتي يلعب فيها تصميم الحروف وطريقة تقديمها وانسجامها مع بعضها البعض الدور الرئيس

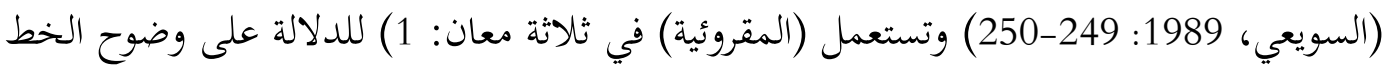

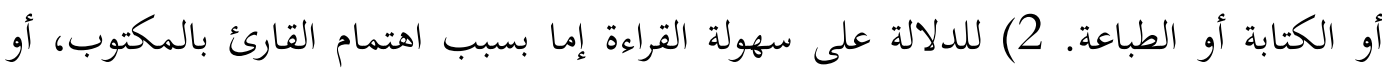


لاستمتاعه وسروره بالكتابة. 3) للدلالة على سهولة الفهم والاستيعاب الراجعة إلى أسلوب الكتابة (الألفي، 2112: 111).

والقابلية المقصودة هنا هي قدرة القارئ على أن يحدد بنجاح، ويستخلص من النص ما يريد أن يستخلصه منه و يتعرف عليه ويميزه. وتقاس القابلية بسرعة قراءة النص وفهمه، أما القرائية فتركز على مدى السهولة في تفسير العلاقات الحادثة بين جمل النص ومكوناته، وسهولة فهمها

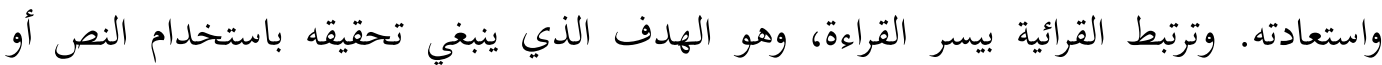
المتن، والتي تتضمن أقصى قدر من السهولة وراحة العين عبر فترة من القراءة المستمرة (speakerman \& Ginger, 2003:31-32). و قد ذكر محمد الألفي: أن الخصائص المؤدية إلى الوضوح في الخط هي التي يجب أن تستحوذ على الاهتمام، وليس الخصائص الجمالية

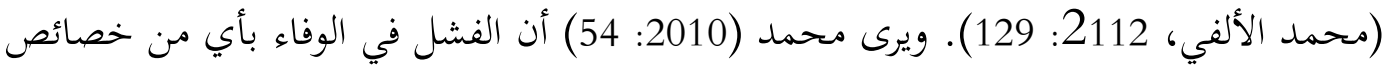
القيمتين الإيضاحية والجمالية في كتابة النص، سيؤدي إلى الفشل في قراءته قراءة سليمة. لذا تنبه الأولون لذلك، و أوجبوا إعطاء كل حرف مجنمالية في كابة النص، سروف الكتابة حقه.

\section{الخط العربي وقواعد رسمه}

لا ينكر منصف أن للخط مكانة سامية في المجال التعليمي، فهو من وشائل التعبير الكتابي، ومثل الخط الجيد في تيسير الأداء، وصدق الإبانة عن أفكار الكاتب مثل التعبير الجيد،

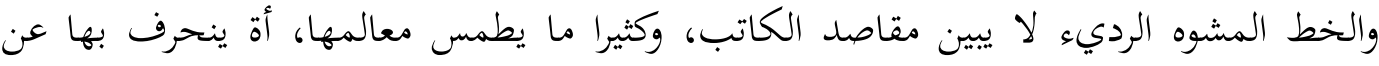

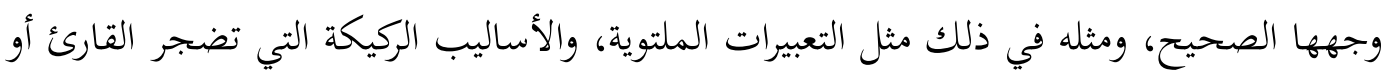

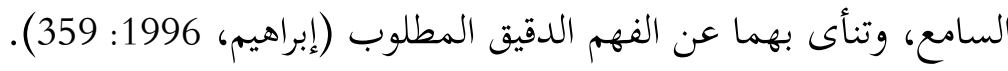
ومع ذلك، يبقى الوضوح، والشرعة، والجمال من أهم أهداف تعليم الخط. والوضوح يتوقف على رسم الحروف رسما لا يجعل للبس محلا، وعلى مراعات التناسب بين الحروف طولا

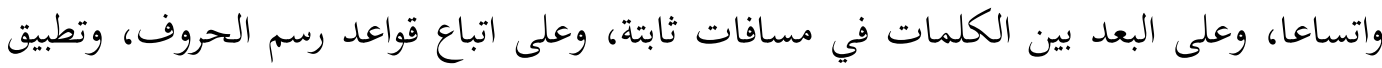

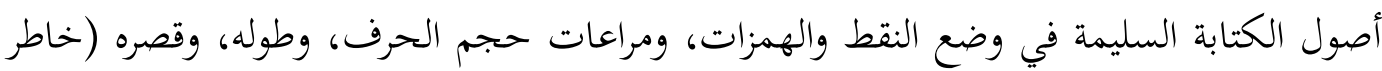

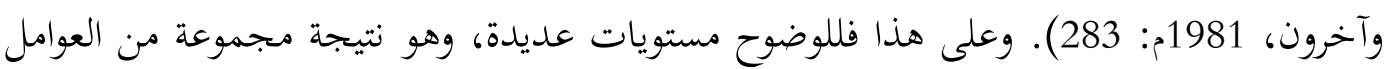

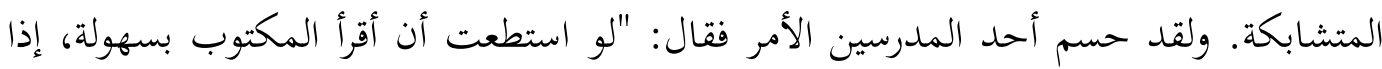

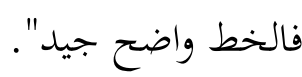

وهناك الخطوط العريضة في تعليم التلاميذ الخط، ويمكن التفصيل للتطرق إليها كما يلي (عبد الناصر،2011): في البداية يجب على التلميذ أن يكون واعيا بورقة الكراس التي يكتب عليها 
، فهي مكونة من سطور خشنة يضع كتابته عليها، وبين كل سطرين ثلاثة خطوط رقيقة بلون مخالف في بعض الكراسات، تحدد حجم كل حرف أعلى أو أسفل السطر. عند التدريب على رسم الحروف، يجب على المعلم تنبيه التلاميذ إلى حجم كل حرف في كل

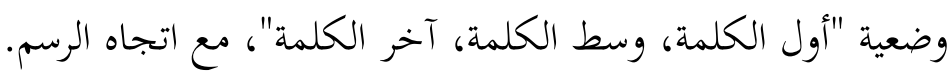

الحروف التي توضع على السطر و ترتفع مسافة واحدة: (بـ ، بـ ، ب ، بب ، ت ، تة ، ت ت

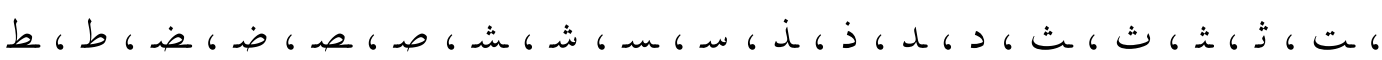

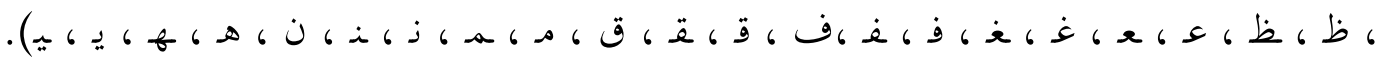
والحروف التي توضع على السطر و ترتفع مسافتين: ( ، أ ، الـ ، ك ، ك ، لـ ، ل ، إشالة الطاء و الظاء). والحروف التي تنطلق من السطر و تنزل مسافة واحدة: (ر ، ر ، ز ، زز ، ي). والحروف

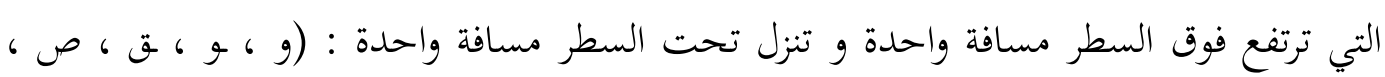
ص ، ض ، ض ، ي). والحروف التي ترتفع فوق السطر مسافة واحدة و تنزل مسافتين: (ج ، ج

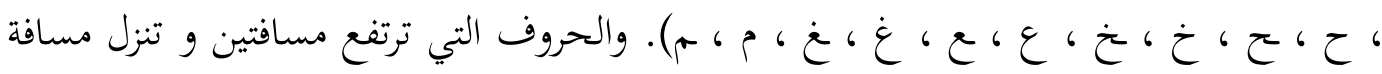
واحدة: (ل) (ل)

بعد التدرب على رسم الحروف منفردة بالحجم و الاتجاه المناسبين، يمر المعلم إلى تصوير الكلمات بالاعتماد على المهارات و التقنيات المكتسبة عند رسم الحروف، و هنا يجب على المعلم أن يشرح كيفية رسم الكلمة بدقة محترما أحجام الحروف المتفق عليها، يطالب التلاميذ بكتابتها مرة واحدة، حتى يتمكن من المراقبة و اكتشاف أخطاء الكتابة و تصحيحها، على السبورة، ثم يأمرهم بكتابتها مرة أخرى. وهكذا إلى أن يتوصل التلاميذ إلى الحد المقبول من الجودة. كما أن للتلاميذ عيوبا عند رسم الكلمات، يجب على المعلم تقويمها، كرفع القلم بعد كل حرف من أجل وضع الحركات أو النقط، وهذا من شأنه أن يشوه الكلمات، فينبهـم إلى عدم وضعها إلا عند الانتهاء من الكلمة، و عدم رفع القلم إلا عند نهاية المقطع الخطي. ( الكلمة "سمع" لها مقطع خطي واحد نكتبها دفعة واحدة دون رفع القلم، والكلمة "مدرسة لها ثلاثة مقاطع وهي: مل، ر، سة). وما يجب تنبيه التلاميذ إليه: عدم وضع النقاط و الحركات قريبة جدا من الحروف حتى لا تلتصق بها، وعدم رسم الحروف متلاصقة ببعضها أو متباعدة كثيرا. ومن العيوب كذلك أن يخطئ التلميذ في كتابة الحرف فيعمد إلى تصحيحة بإعادة كتابته بالضغط عليه بالقلم وعليه يجب تجنب تصحيح الخطإ بخطإ آخر . 
عند تدريب التلاميذ على نسخ الجمل، يتجنب المعلم مطالبتهم بكتابتها دفعة واحد من

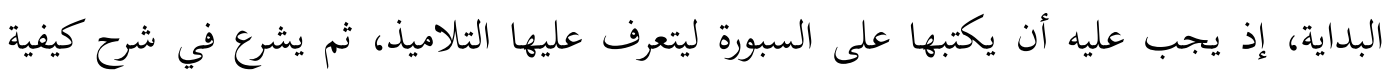

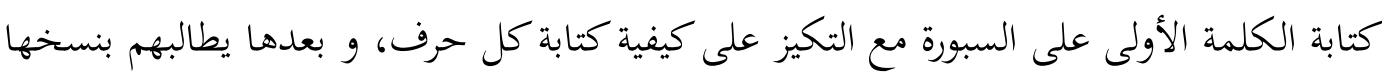

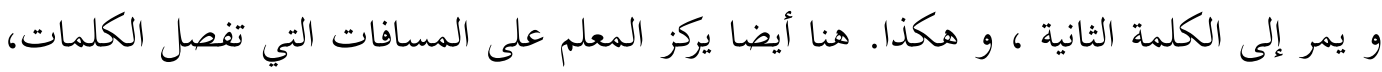
إذ لا يجب أن تكون متقاربة لحد الالتصاق ولا متباعدة كثيرا للمحافظة على تناسق الجملة .

\section{المبحث في نماذج كتابة الطلبة بقسم تعليم اللغة العربية}

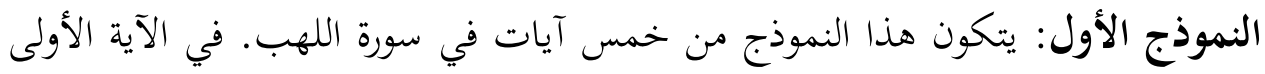
رسم الياء في كلمة (أبي) على السطر ويشبه النون. وفي الآية الثانية حرف الغين في كلمة فئ (أغنى)

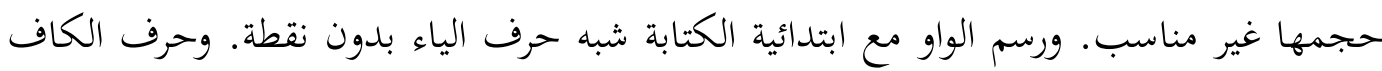

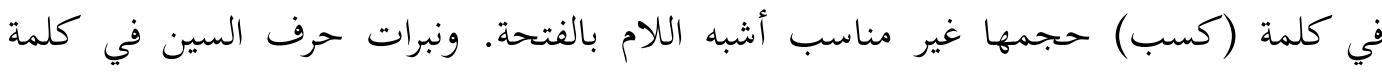
(سيصلى) في الآية الثالثة لم تبين كما ينبغي. وفي الآية الرابعة رسم الميم والراء في كلمة (وامرأته)

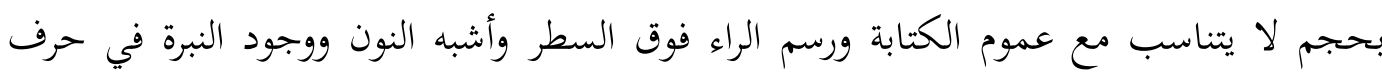

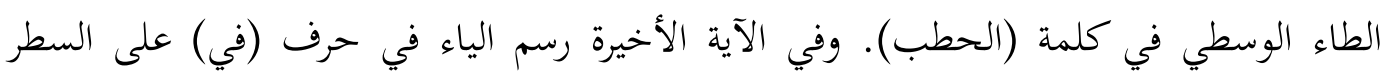

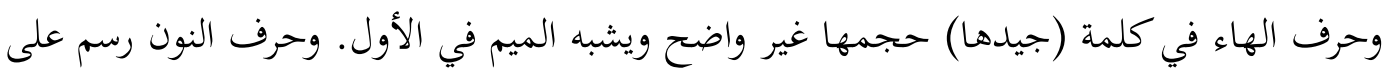
السطر . وبعض النقاط في هذا النموذج تشبه علامة الفتحة والكسرة. الصورة 1. نموذج كتابة سورة اللهب في كراسة أحد الطلبة

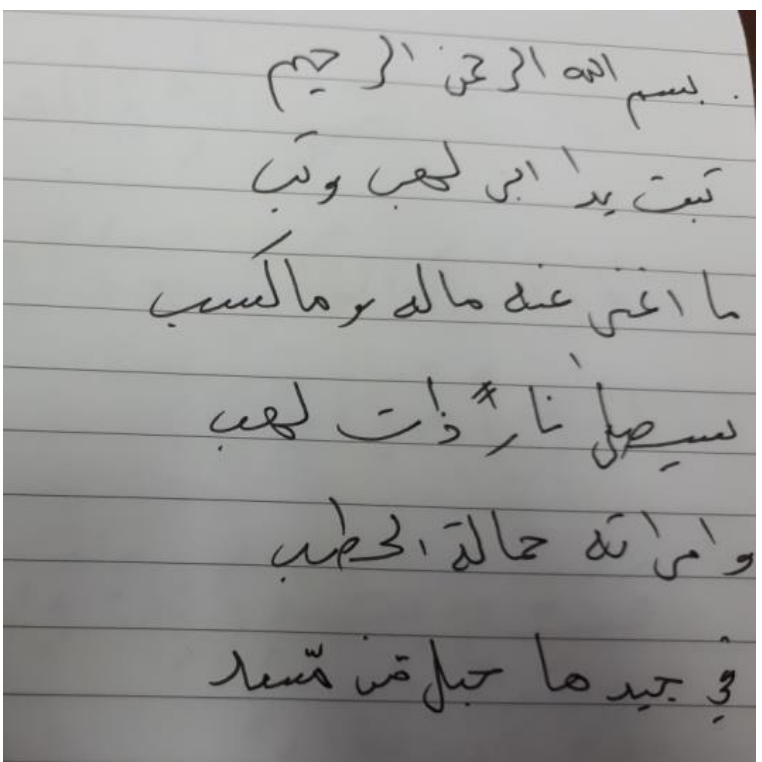




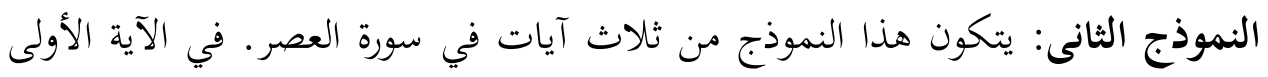

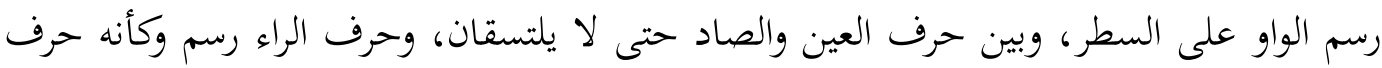

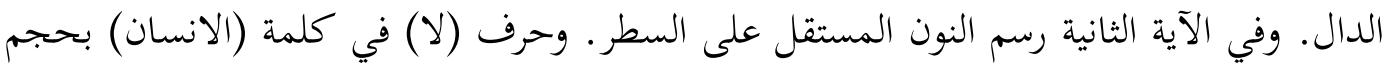

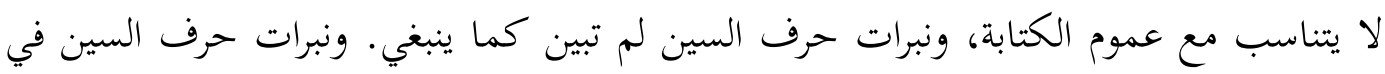

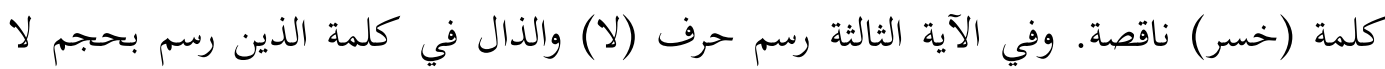

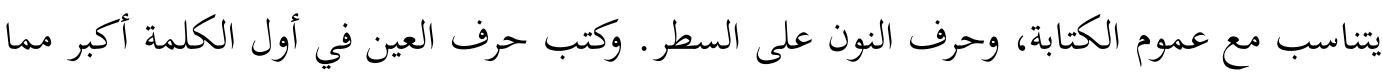

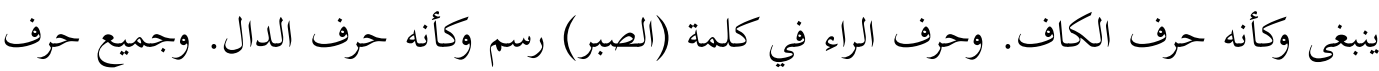

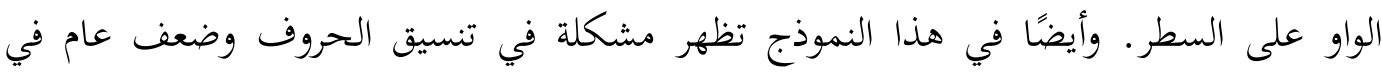
الإيقاع وفي وضع المسافة المناسبة بين الكلمات.

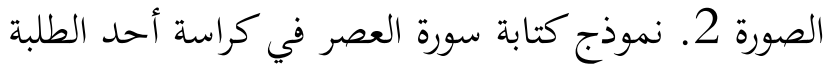

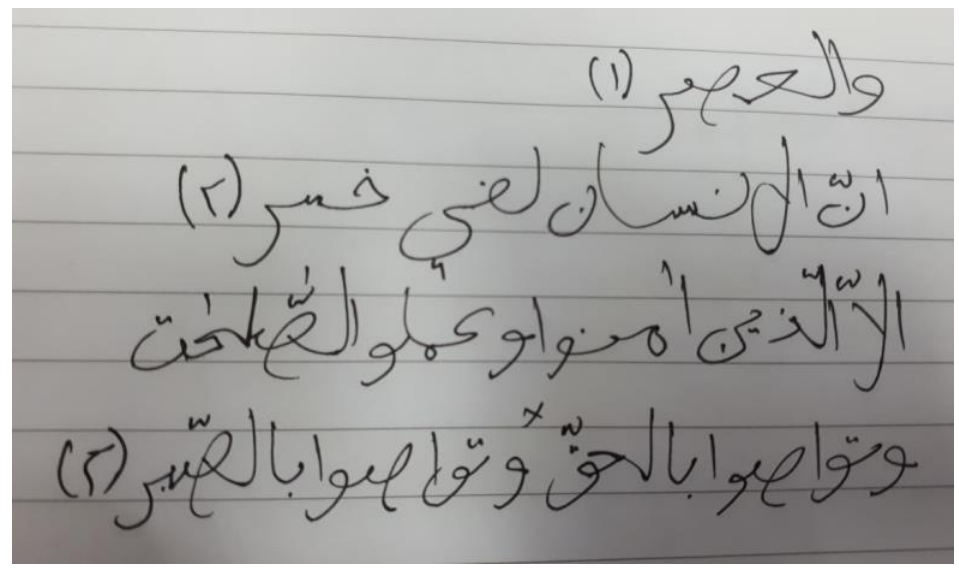

النموذج الثالث: يتكون هذا النموذج من خمس آيات في سورة الناس. في الآية الأولى

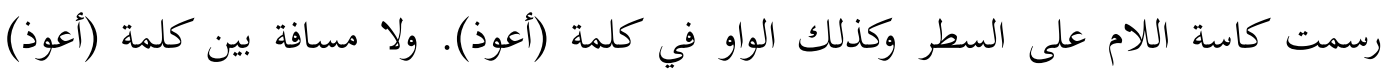

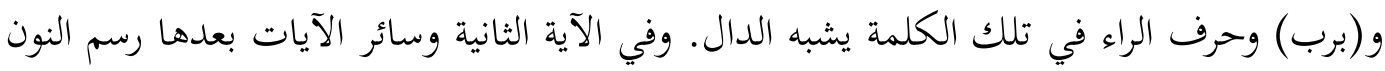
بحجم لا يتناسب مع عموم الكتابة على السطر وبدون نقطة. ويشبه حرف الراء في كلمة (شر) بحرف النون أو كاسة السين، وحرف القاف في كلمة (خلق) على السطر. وفئ وفئ الآية الثالثة لا

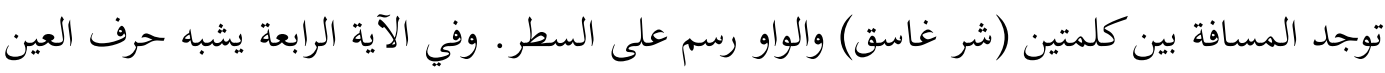
في الوسط بحرف الحاء في كلمة (العقد). الصورة 3. نموذج كتابة سورة اللفلق في كراسة أحد الطلبة 


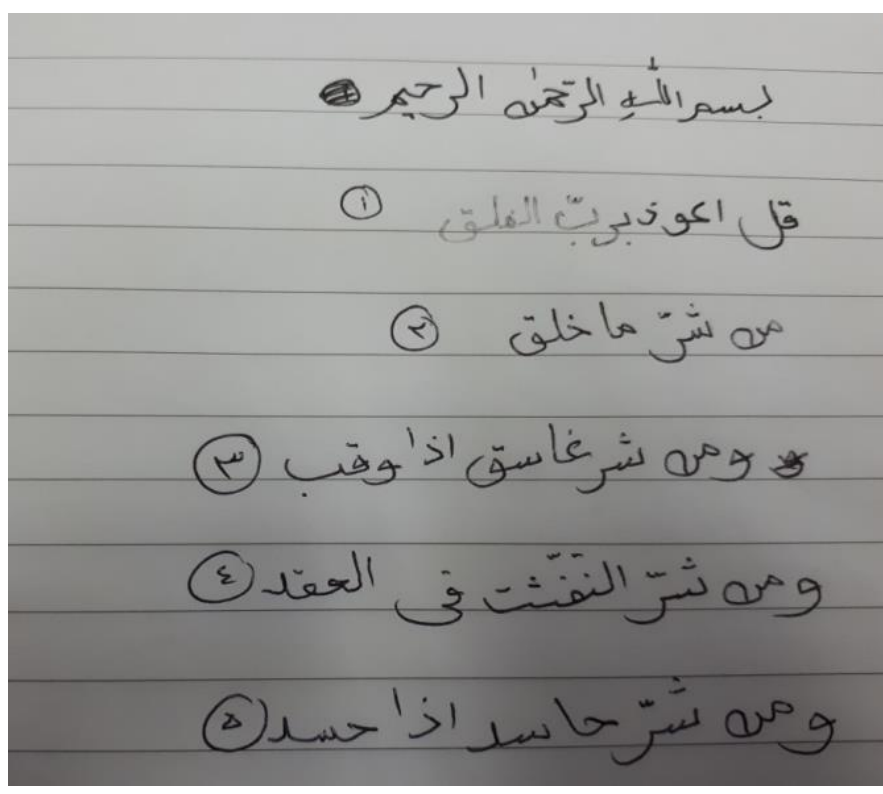

النموذج الابع: يتكون هذا النموذج من خمس آيات في سورة القريش. في الآية الأولى رسم أخير الفاء في كلمة (لايلاف) غير واضح وكذلك نبرات الشين في كلمة (قريش). وفي الآية الثانية لا توجد النبرة لحرف الصاد في كلمة (الصيف). وفي الآية الثالثة يشبه حرف العين في الوسط في كلمة (فليعبدوا) بحرف الحاء، واللام في تلك الكلمة قصيرة جدا مقارنة مع الياء بعده. واتصال الطاء والعين في (أطعمهم) حجمه غير مناسب. الصورة 4. نموذج كتابة سورة القريش في كراسة أحد الطلبة

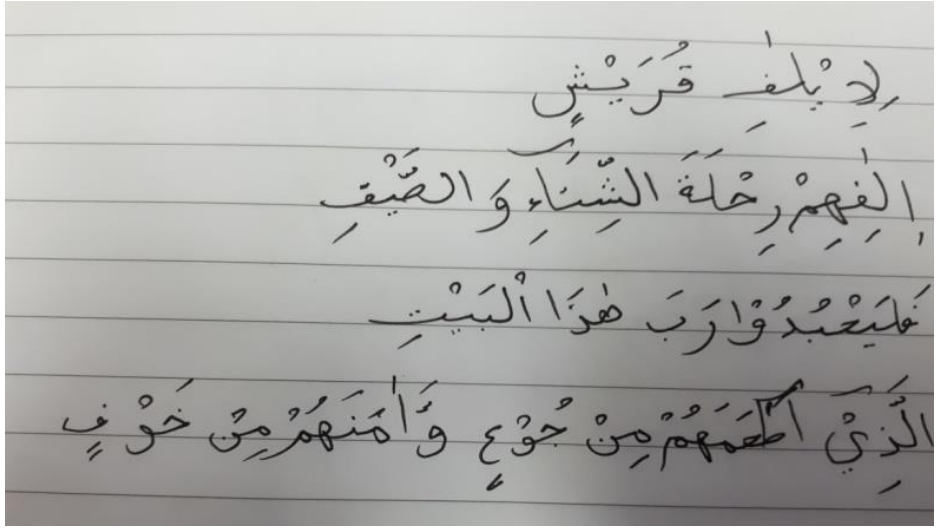

النموذج الخامس: يتكون هذا النموذج من سبع آيات في سورة الفاتحة. رسم النون في كلمة (الدين) على السطر. ويشبه حرف العين في الوسط في جميع الآيات بحرف الحاء. وحجم الهاء الذي يتصل بحر الدال في كلمة (اهدنا) غير مناسب مع عموم الكتابة وكذلك اتصال الهاء بحرف الميم في كلمة (عليهم) في الآية الأخيرة رسم في مساحة غير كافية. وفي الآية الأخيرة لا توجد النبرة لحرف الصاد في كلمة (صراط) وكذلك في حرف الضاد في كلمة (المغضوب). وكلمة أنعمت غير مقروءة جيدا لأن العين في الوسط غير واضح جدا. 


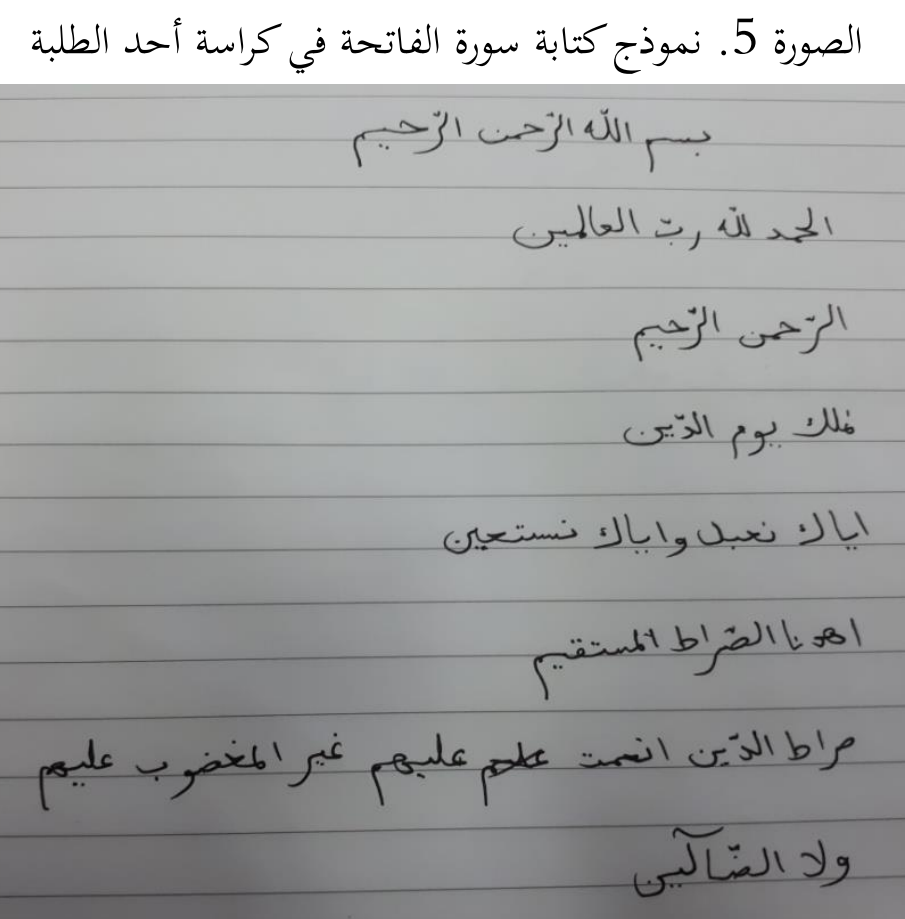

النموذج السادس: يتكون هذا النموذج من ثلاث آيات في سورة الفتح. رسمت النبرة لحرف الصاد في كلمة (نصر) غير واضحة. والهاء في ألفاظ الجلالة يرتفع أكثر من اللام. وحرف الخاء في كلمة (يدخلون) و الجيم في كلمة (أفواجا) والحاء في كلمة (بحمد) حجمهم لا يتناسب مع عموم الكتابة. والنون في كلمة (يدخلون) و (كان) رسم فوق السطر. الصورة 6. نموذج كتابة سورة الفتح في كراسة أحد الطلبة

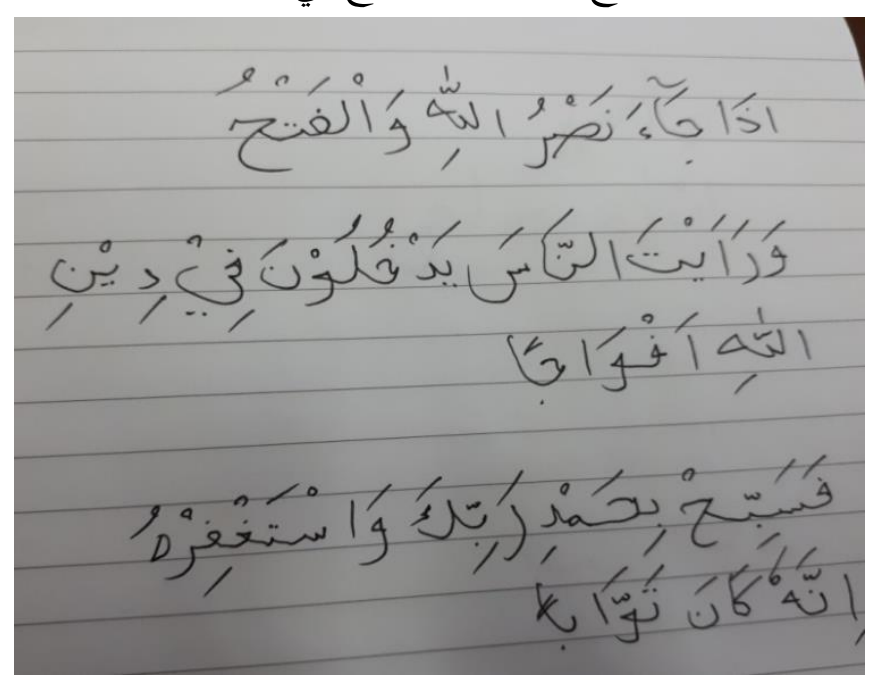

النموذج السابع: يتكون هذا النموذج من أريع آيات في سورة الإخلاص. رسم الميم في الأخير على السطر وكذلك جميع حرف الواو، ورسم النون في كلمة (يكن) على السطر أيضا. وفي هذه الكتابة عامة عدم الالتزام بسطر الحروف والسطر في الكراسة. الصورة 7. نموذج كتابة سورة الإخلاص في كراسة أحد الطلبة 


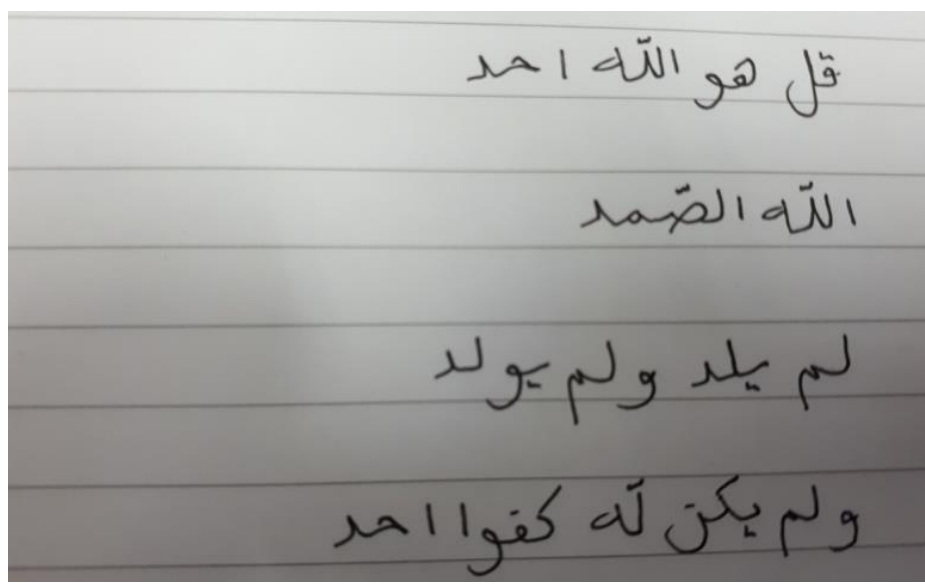

النموذج السابع: يتكون هذا النموذج من خمس آيات في سورة الفيل. رسم الفاء في

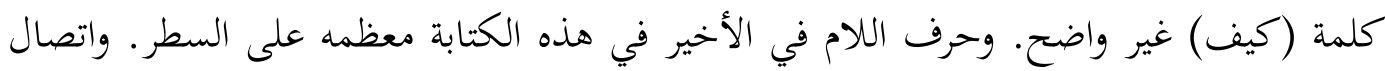

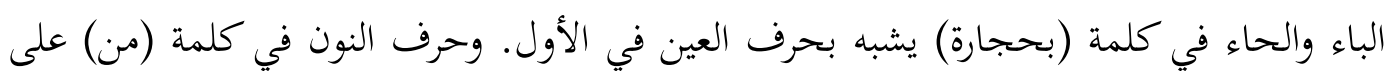
السطر.

الصورة 8. نموذج كتابة سورة الفيل في كراسة أحد الطلبة

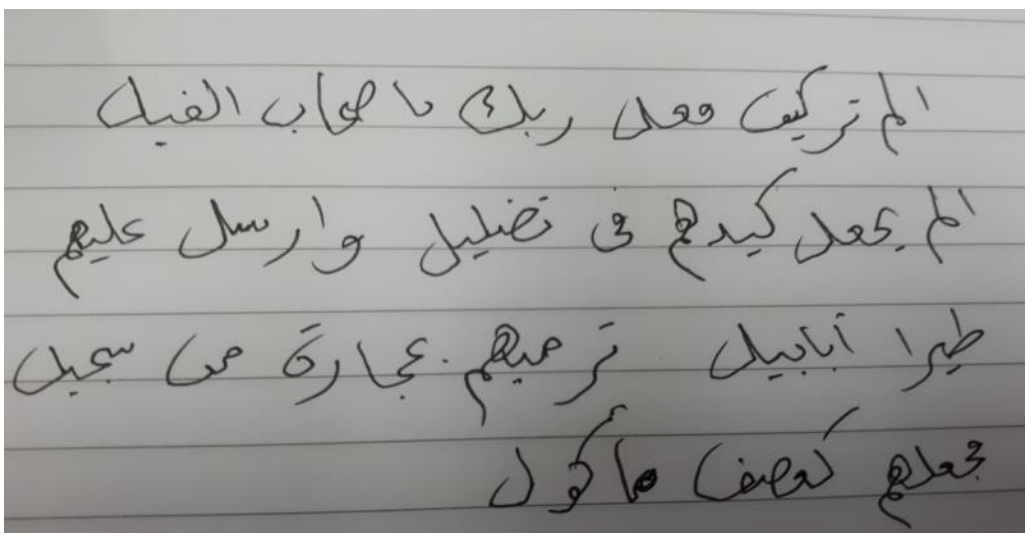

النموذج التاسع: يتكون هذا النموذج من ثلاث آيات في سورة الكافرون. في الأية

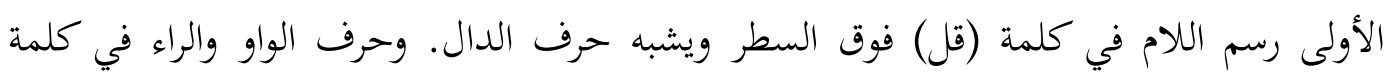

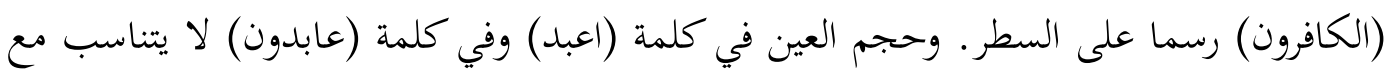
عموم الكتابة. ويشبه حرف العين الوسطي في كلمة (تعبدون) بحرف الحاء، ورسم حرف العين فئل الواو والراء على السطر. الصورة 9. نموذج كتابة سورة الكافرون (1-3) في كراسة أحد الطلبة 


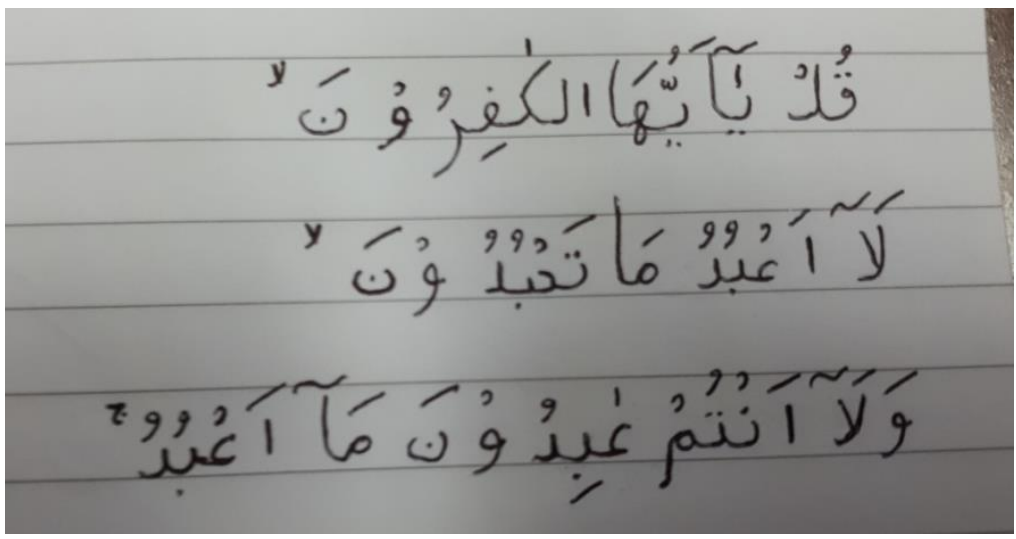

النموذج العاشر: يتكون هذا النموذج من ثلاث آيات في سورة الكوثر. رسم حرف العين والطاء منفصلا في كلمة (أعطينك)، ووجود النبرة في حرف الطاء. رسم الواو في كلمة (الكوثر)

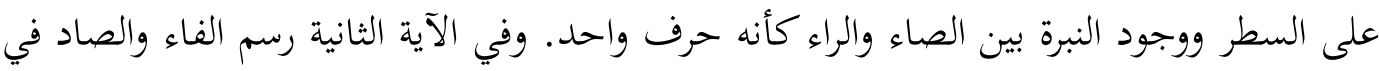

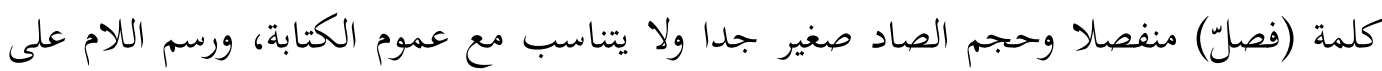
السطر. وفي كلمة (وانحر) رسم الألف صغير جدا وجود النبرة بين الصاء والراء. وفي الآية الأخيرة

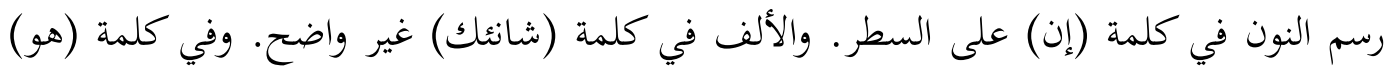

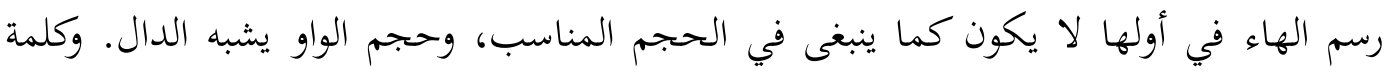
(الأبتر) غير مقروءة جيدا وبمساحة غير كافية. الصورة 10. نموذج كتابة سورة الكوثر في كراسة أحد الطلبة

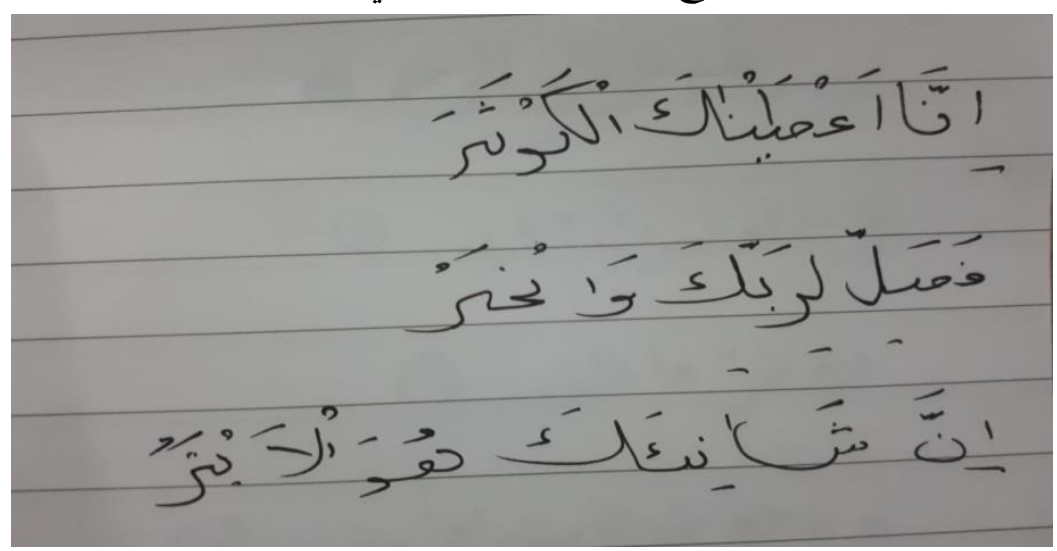

تحليل الأخطاء الشائعة في رسم الحروف العربية لدى الطلبة في قسم تعليم اللغة العربية

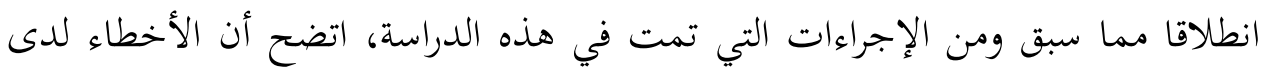

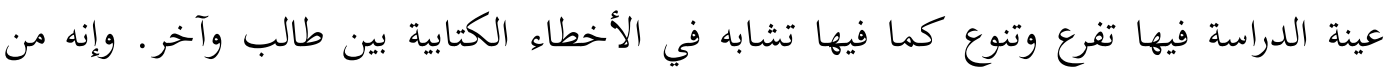

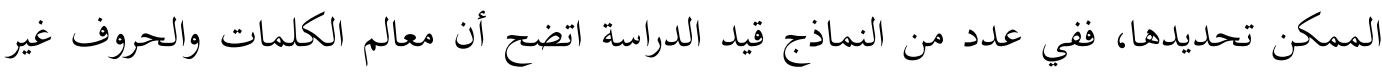


مقروءة تمامًا ويجعل للبس محلا، وفي تفصيلات رسم الحروف اتضح أن هناك عدد من عدم

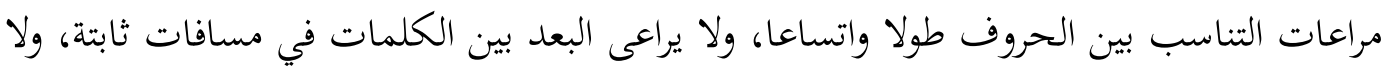

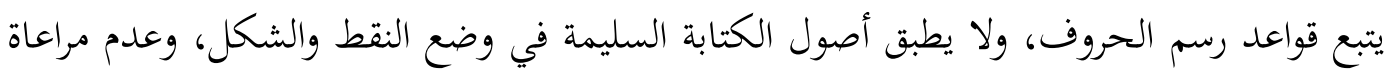

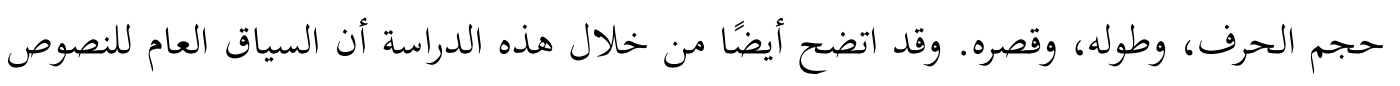

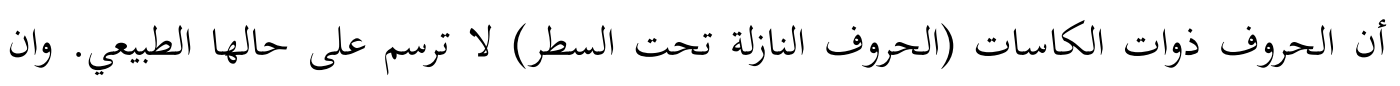
عدم الالتزام بسطر الحروف النازلة تحت سطر الكتابة الأساسي.

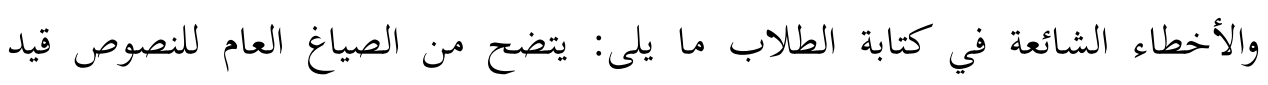

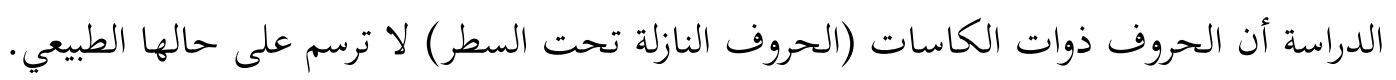

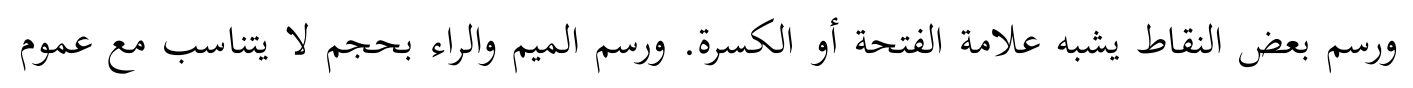

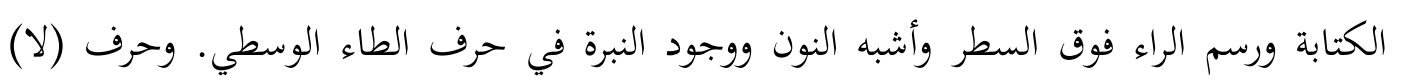

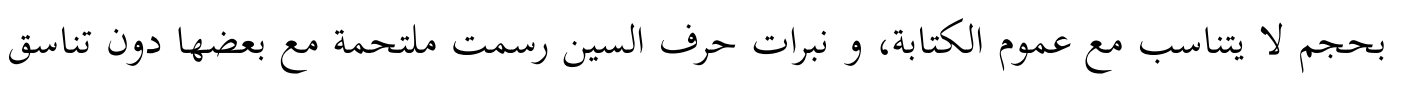

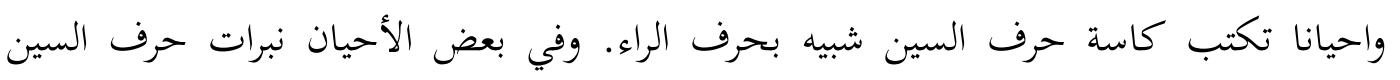
كانت ناقصة مما ينبغي.

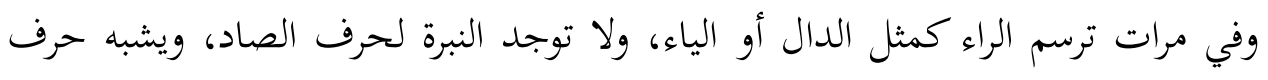

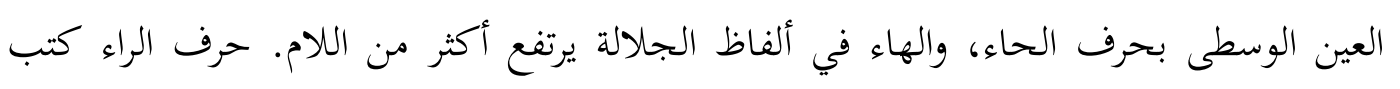

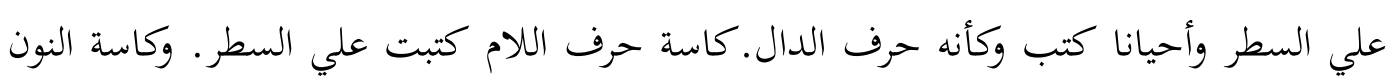

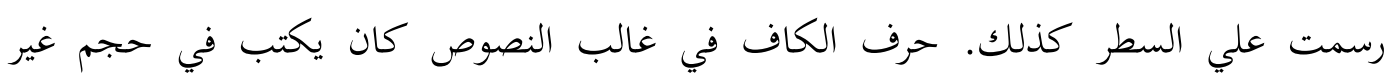
مناسب. حرف الصاد والضاد رسم في أحايين كثيرة من غير نبرة. وفي أحيان رسم صغئ صغيرا قياسًا

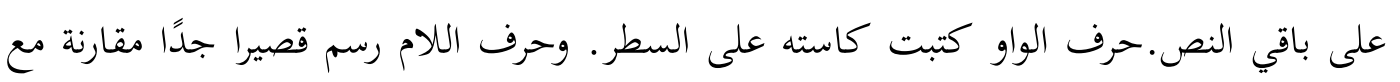
الإلف.

ويمكن وجود الاقتراحات لتحسين وتصحيح تلك الأخطاء بما يلى: 1) تصميم كراسات

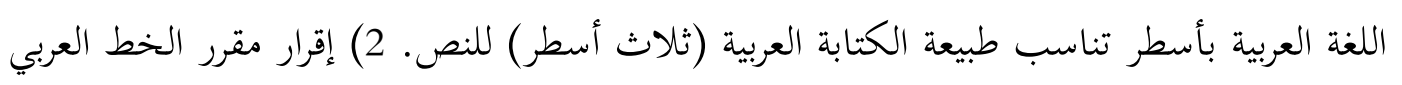
على الطلاب. 3) تحسين طريقة تعليم الخط. 4) تأهيل المعلمين في محيط الخط العربي. 5)

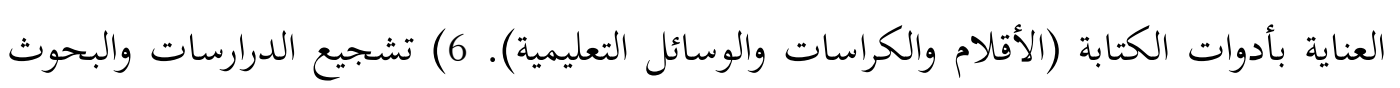
في مجال تحسين الكتابة لدى التلاميذ.

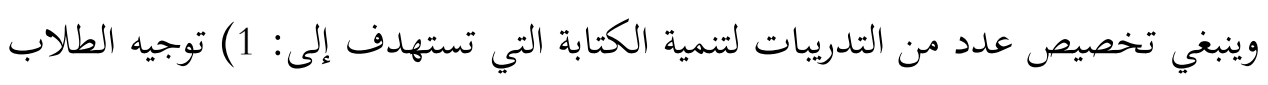

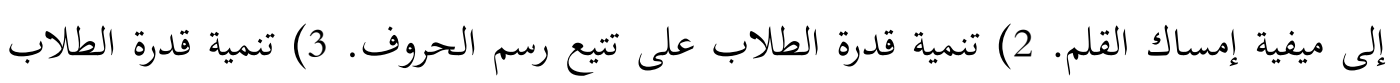

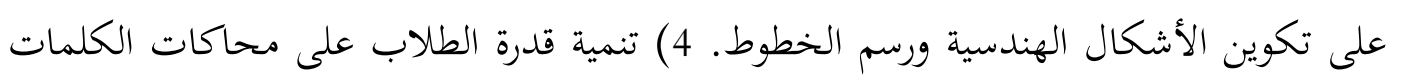


وكتابتها بشكل مقروء ومراعات تناسب المسافات بين الحروف والكلمات. 5) تنمية قدرة الطلاب على التمييز بين الحروف في أوضاعها المختلفة رسما.

الخاتمة

وفي نهاية البحث بتوفيق الله ولطفه أستنبط أن هناك عديد من الأخطاء والمشكلات

التي يواتجهها الطلاب في كتابة الحروف العربية في قسم تعليم اللغة العربية، ولاسيما في الأقسام الأخرى. ولذا، فعلى المعلم أن يهتم جيدا بكتابة الطلاب ويصصحها قبل أن يكونوا المدرسين في المستقبل. وأقول لكم: فهذا ما هداني الله إليه، وما أعانني عليه، فإن كنت قد أصبت فذلك فضل الله، وإن كانت الأخرى فحسبي أني بشرٌ أخطئ وأصيب، وأستعيذ بالله من الشيطان الرجيم. وآخر دعوانا أن الحمد لله بنعمته تتم الصالحات وبالله التوفيق.

قائمة المراجع

الرفاعي، أحمد حسن. 1998. مناهج البحث العلمي. الأردن: دار وائل للنشر والتوزيع.

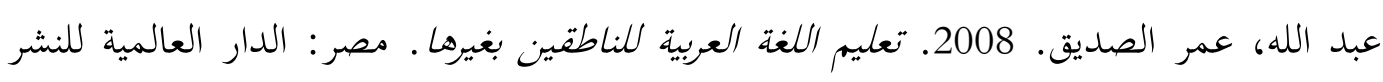
والتوزيع.

مدكور، على أحمد. 2016. تلدريس فنون العربية. القاهرة: دار الفكر العربي. محمد، سعد الدين عبد الحميد.2010. جماليات الخطوط الطباعية العربية ووظيفتها. رسالة

دكتوراه، جامعة السودان للعلوم والتكنولوجيا، كلية الفنون الجميلة والتطبيقية.

الألفي، محمد. 2005. عناصر الرداءة المعوقة لقراءة خطوط دارسي العربية من غير أهلها. مجلة

العربية للناطقين بغيرها، معهد اللغة العربية بجامعة إفريقيا العالمية ـ العدد الثاني.

مناصرة، يوسف عثمان. دون السنة. تقويم منهج القراءة والكتابة في المرحلة الابتدائية الدنيا. أردن: دكتوراه عين شمس.

الناقة، محمود كامل. 2017. تعليم اللغة العربية لأبنائها: المداخل والطرائق والفنيات

$$
\text { والإستراتيجيات المعاصرة. القاهرة: دار الفكري العربي. }
$$

إبراهيم، عبد العالم. 1996. الموجه الفني لمدسري اللغة العربية. القاهرة: دار المعارف. 
الأخطاء الثائعة في كتابة الحروف العربية لدى الطلاب في قسم تعليم اللغة العربية

خاطر، محمد رشدي وآخرون. 1981. طرق تلدربس اللغة العربية والتربية الدينية في ضوء الاتجاهات التربوية الحديثة. القاهرة: دار المعرفة.

أمازيغ، . https://www.djelfa.info/vb/archive/index.php/t-722927.html

Speakerman, Erik \& E.M. Ginger. 2003. Stop Stealing Sheep \& Find Out How Type Works. 2nd Edition, Adobe press, California. USA. 